\title{
Interaction between Emotion and Memory: Importance of Mammillary Bodies Damage in a Mouse Model of the Alcoholic Korsakoff Syndrome
}

\author{
Daniel Béracochéa \\ Laboratoire de Neurosciences Cognitives, UMR CNRS 5106, Université de Bordeaux \\ 1, Avenue des facultés, 33405 Talence, France
}

SUMMARY

Chronic alcohol consumption (CAC) can lead to the Korsakoff syndrome (KS), a memory deficiency attributed to diencephalic damage and/or to medial temporal or cortical related dysfunction. The etiology of KS remains unclear. Most animal models of KS involve thiaminedeficient diets associated with pyrithiamine treatment. Here we present a mouse model of CAC-induced KS. We demonstrate that CACgenerated retrieval memory deficits in working/ episodic memory tasks, together with a reduction of fear reactivity, result from damage to the mammillary bodies (MB). Experimental lesions of $M B$ in non-alcoholic mice produced the same memory and emotional impairments. Drugs having anxiogenic-like properties counteract such impairments produced by CAC or by MB lesions. We suggest (a) that $M B$ are the essential components of a brain network underlying emotional processes, which would be critically important in the retrieval processes involved in working/ episodic memory tasks, and (b) that failure to maintain emotional arousal due to MB damage can be a main factor of CACinduced memory deficits. Overall, our animal model fits well with general neuropsychological and anatomic impairments observed in KS.

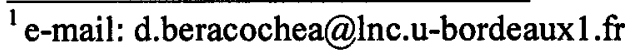

\section{KEYWORDS}

alcohol, ethanol, diencephalons, thalamus,-anxiety, thiamine deficiency

\section{INTRODUCTION}

The Wernicke-Korsakoff syndrome is one of the most serious consequences of long-term alcohol abuse. The specific etiology of this syndrome remains under debate, even though heavy and longterm alcohol use is the most common association with Wernicke-Korsakoff syndrome. Nevertheless, according to several authors, the Korsakoff syndrome (KS) is caused by a lack of thiamine (vitamin B1), which affects the brain and nervous system. Indeed, the excessive use of alcohol is often the cause of thiamine deficiency, insofar as many heavy drinkers have poor eating habits. Thiamine is converted to thiamine pyrophosphate, which serves as a cofactor for several enzymes involved in glucose utilization. Alcohol interferes with active gastrointestinal transport, and chronic liver disease leads to a decreased activation of thiamine pyrophosphate from thiamine, as well as reducing the capacity of the liver to store thiamine. The particular sensitivity of thiamine metabolism to alcohol intoxication has been documented. As a case in point, Molina et al. (1994) showed that chronic alcoholics exhibit a low serum level of thiamine but not of other vitamins; yet, the serum 
level of thiamine was weakly correlated with cognitive performance, as opposed to the duration of alcohol intake and education. The thiaminedeficiency hypothesis has also been strengthened by the observations of the Wernicke-Korsakoff syndrome in non alcoholic patients (Parkin et al., 1991).

Korsakoff syndrome is part of the WernickeKorsakoff syndrome, which comprises two separate but related stages-Wernicke's encephalopathy and Korsakoff psychosis. It is noteworthy that not all cases of Korsakoff are preceded by an episode of Wernicke. Wernicke encephalopathy symptoms involve involuntary eye movements, poor balance, staggering gait or inability to walk, drowsiness, and confusion. Such symptoms can be most often reversed by high doses of thiamine injected into a vein or muscle. In contrast, the memory loss in Korsakoff patients is insensitive to thiamine injection (Fellgiebel et al., 2003) and is thought to be an outcome of the structural brain damage and thus to be largely irreversible (attempts to explore neuropharmacological therapies have yielded mixed results: Martin et al., 1995; Moffoot et al., 1994; O'Carroll et al., 1994).

Anterograde amnesia is characterized by a difficulty to acquire new information and constitutes the main KS symptom. The memory loss would mainly result from an impairment of encoding processes (Butters 1985) and/or a failure of retrieval ones (Lhermitte \& Signoret, 1972; Warrington \& Weis-Krantz, 1974) as opposed to amnesia resulting from medial temporal damage, characterized by a more severe accelerated forgetting over time (Huppert \& Piercy, 1976; Thompson, 1981). According to some authors, however, both diencephalic and temporal amnesia share common features so that they would be almost indistinguishable on neuro-psychological grounds, insofar as diencephalic amnesia can be due to a disconnection between the diencephalon and the medial temporal lobe (Mayes et al., 1988). Other KS symptoms consisted of a difficulty in learning new skills, a marked sensitivity to interference, an alteration of the temporal order judgment, and a deficit of spatial organization (Butters, 1985). Confabulation and a lack of insight into the condition are also observed (for example, some patients with great gaps in their memory can believe that their memory is functioning normally); in addition to these cognitive deficits, disturbance of affective judgments, apathy in some cases, are also frequently observed (Johnson et al., 1985; Cabanyes, 2004).

Given the heterogeneity of the neuropsychological data, three hypotheses have been formulated to localize the neural dysfunction responsible for the memory failure of Korsakoff patients.

1. The first hypothesis is that the relevant functional damage is restricted to the diencephalons.

2. A second hypothesis is that additional brain areas in the medial temporal region are affected; thus, Butters and Stuss (1989) suggested that diencephalic amnesia could arise from disrupted connections between the diencephalon and medial temporal lobe structures, which would account for the high degree of similarity between the amnesic impairments resulting from diencephalic or temporal damage.

3. A third hypothesis is that functional impairments are widespread, encompassing multiple cortical areas (Paller et al., 1997).

Lesions of the mammillary bodies (MB) of the hypothalamus are large and most frequently observed as opposed to other brain damage (Victor et al., 1971; Reed et al., 2003). Mammillary bodies exhibit distinct anatomical features in mammals. In rats, the mammillary region consists of a complex set of nuclei; it is constituted mainly by the lateral, the medial, and the supra-mammillary nuclei. The MB themselves are divided into two groups, the medial and lateral nuclei. The MB receives dense afferent connections from the hippocampus through the post-commissural fornix, 
which terminate mainly into the medial MB nucleus (Swanson \& Cowan, 1977; Meibaach \& Siegel, 1977). The MB sends efferent connections to thalamic nuclei via the mammilllo-thalamic tract. The thalamic outputs of the medial and lateral MB nuclei are topographically distinct: the medial MB nucleus sends outputs to the anteromedial and anteroventral thalamic nuclei, whereas the lateral MB nucleus sends outputs to the anterodorsal thalamic nucleus (Cruce, 1975; Seki \& Zio, 1984). The medial MB nucleus has reciprocal connections with the ventral tegmental nucleus of Gudden, whereas the lateral MB nucleus has reciprocal connections with the dorsal tegmental nucleus of Gudden; they also project to different areas of the reticular tegmental nucleus (Cruce, 1977; Hayakawa \& Zyo, 1984; 1985; Allen \& Hopkins, 1990). Furthermore, both the lateral and medial MB nuclei are also inner-vated by the suprammamillary and the tuberomammillary nuclei, as well as by the frontal cortex, the septal area, and the medial enthorinal cortex (Allen \& Hopkins, 1989; Gonzalo-Ruiz et al. 1992; Shibata, 1988). This overall pattern of connections, mainly drawn from the study of the rat brain, is also found in the primate brain.

As a whole, the topographically distinct anatomical connections of the lateral and medial MB nuclei have suggested that both nuclei belong to two parallel systems, which have been proposed to explain the functional involvement of the $\mathrm{MB}$ in memory processes (Vann \& Aggleton, 2004). Both systems would contribute either separately or synergistically (given some of their common sites of convergence) to different processes, such as the directional firing of head direction cells in the anterodorsal thalamus, the transmission of the hippocampal theta rhythm to other limbic sites, or the treatment of allosteric information.

Interestingly, despite the importance of the anatomical interactions of the MB with the medial temporal and diencephalic areas, the neuropathology of KS stresses more the importance of damage in the diencephalon, including the medial thalamus and connections with the medial temporal lobes, rather than MB damage as a key factor of Korsakoff amnesia. Thus, lesions of thalamic nuclei (mainly of the mediodorsal thalamus or of the anterior thalamic nuclei), in the absence of MB lesions, were found to be sufficient to produce a severe anterograde amnesia. So far, thalamic damage is thought to be a key factor to produce amnesia (Victor et al., 1971; Markowitch, 1982; Mair, 1994; Harding et al., 2000). In keeping with this idea, some studies have also reported no memory loss in Wernicke-Korsakoff patients in whom degeneration into the MB was nevertheless observed (Victor et al., 1971) even though, conversely, existing clinical data show that neuroanatomical lesions restricted to the $\mathrm{MB}$ can induce temporal order judgment deficits and an exaggerated vulnerability to interference, in the absence of any other brain lesions (Hildebrandt et al., 2001).

The issue of whether hippocampal lesions or indirect hippocampal dysfunction is a significant feature of KS remains open. Indeed, hippocampal and diencephalic damage generates some common neuropsychological deficits. Further, on the one hand hippocampal damage was shown to result from a direct neurotoxicity of alcohol (Freund, 1973; Walker et al., 1980), and post-mortem neuropathology of Korsakoff subjects has evidenced hippocampal involvement in some cases (see also Mayes et al., 1988). On the other hand, animal studies have also demonstrated that discrete lesions of the MB or diencephalic damage can disrupt hippocampal cholinergic activity (Béracochéa et al., 1995b; Savage et al., 2003). Thus, Vann and Aggleton (2004) also pointed out the importance of medial temporal dysfunction resulting from $\mathrm{MB}$ damage in KS and diencephalic amnesia.

The importance of temporal damage as a critical factor to induce memory loss in Korsakoff patients is challenged, however, by studies using various structural or functional neuro-imaging 
techniques. Such studies showed in KS patients normal hippocampal size (Squire et al., 1990) and spared hippocampal metabolism (Paller et al., 1997). In contrast, in addition to the hypothalamic and diencephalic alterations, some of these studies have often evidenced large cortical hypometabolism associated with cognitive cortical dysfunction, suggesting that the influence of diencephalic damage on cortical function areas would play an essential role in memory loss of KS subjects (Paller et al., 1997; Kopelman, 1995; see also Brokate et al., 2003).

\section{ANIMAL MODELS OF KS USING THIAMINE-DEFICIENT DIETS}

In the field of learning and memory, animal models have been instrumental in shaping our understanding of how normal and damaged brains process information. Thus, animal investigations have allowed the description of memory in terms of multiple systems-competing or interacting or functioning in parallel-depending on the cognitive demand or on the psychological nature of the task.

Given the etiologic data, most attempts to produce an animal model of the KS have involved thiamine deficiency as a tool to induce the neuropsychological and cerebral damage observed in this pathology. The pyrithiamine-induced thiamine deficiency (PTD) model often consisted of a combination of a thiamine-deficient diet associated with the application of pyrithiamine, a thiamineantagonist. Most of the data using the PTD model have shown important memory loss and lesions predominantly located in the diencephalic areas, but damage was also observed in other brain areas (the basal forebrain, several cortical areas, and the MB (Irle \& Markowitsch, 1983; Mair et al., 1988; Joyce, 1994; Mumby et al., 1995; Langlais \& Zhang, 1997). As suggested for Korsakoff patients, damage into the mediodorsal thalamus has been thought to be mainly responsible for the deficits of PTD animals, since experimental mediodorsal thalamic lesions in monkeys and rodents produced memory impairments similar to those resulting from PTD or from Korsakoff amnesia (Zola-Morgan \& Squire, 1985). In addition, the PTD model also allows the study of the relationships between diencephalic damage and medial temporal dysfunction. Indeed, using tasks involving spontaneous alternation, Savage et al. (2003) demonstrated that PTDtreated rats exhibiting diencephalic damage also show a reduction of the release of acetylcholine efflux in the hippocampus. There is evidence, therefore, that the hippocampus is not fully activated in memory tasks in rats suffering from diencephalic damage.

Despite its interest in producing diencephalic amnesia and in studying the interaction between the diencephalon and related brain structures on memory processes, however, the PTD model does not provide clear-cut evidence in favor of the predominance of thiamine deficiency as the main causal factor of Korsakoff amnesia. Indeed, pyrithiamine administration is a drastic way to deplete thiamine metabolism, which largely encompasses the common physiological state of thiamine depletion in Korsakoff patients. In fact, most studies using a thiamine-deficient diet alone (in the absence of combined pyrithiamine administration) evidenced some degree of memory loss in thiaminedeficient animals (Witt \& Goldman-Rakic, 1983a-b; Mair et al., 1988). Nevertheless, negative findings have also been reported (Homewood et al., 1991; Tako et al, 1991). Moreover, the brain lesions induced by thiamine deficiency were less severe than in PTD and inconsistent from one study to another. For example, Witt and Goldman-Rakic $(1983 a-b)$ failed to identify mediodorsal thalamic damage in monkeys submitted to a thiaminedeficient diet, as opposed to findings reported by Mair et al. (1988) in rodents; moreover, as opposed to PTD, a thiamine-deficient diet failed to produce the hypothalamic damage often observed 
in Korsakoff amnesia. Indeed, in a comparative study using independent groups submitted either to chronic alcohol consumption or to a severe thiaminedeficient diet, we found that only alcohol-treated mice exhibited a working memory deficit and large MB damage (Tako et al., 1991). The sparing of the $\mathrm{MB}$ in thiamine-deficient animals is not specific to mice; indeed, other studies have also shown that the MB are not altered by a thiamine-deficient diet, both in monkeys (Witt \& Goldman-Rakic, 1983a-b) and in rats (Mair et al., 1988).

Interestingly, the studies using chronic alcohol diets reported more severe memory impairments than when using a thiamine-deficient diet without pyrithiamine administration (Homewood et al. 1997; Tako et al; 1991; Ciccia \& Langlais, 2000). Other studies also highlighted the finding that the interaction between CAC and the age of the subjects is of critical importance in alcoholinduced dysfunction (Krazem et al., 2003). That several studies have demonstrated a direct neurotoxicity of alcohol (Freund, 1973; Walker et al., 1980 ) suggests that long-term alcohol intake could be a causal factor of specific neuropathological features of KS. Indeed, numerous reports suggest that a combination of alcohol consumption and thiamine deficiency is not only required to produce severe, long-lasting memory impairment but also constitutes the main neurological damage of $\mathrm{KS}$ (Homewood \& Bond, 1999).

\section{A MOUSE MODEL OF KS INDUCED BY CAC: IMPORTANCE OF MB DAMAGE.}

An animal model of Korsakoff amnesia using $\mathrm{CAC}$ as the sole etiologic factor is lacking. Therefore, the scope of our studies was to determine whether CAC in mice could produce memory loss and neuroanatomical damage (mainly diencephalic in the broader sense, including hypothalamic damage) that could resemble that observed in Korsakoff patients.

In our studies, mice of the Balb/c strain were submitted to a forced consumption of alcohol $(12 \% \mathrm{v} / \mathrm{v})$ for several months (either 6 or $12 \mathrm{mo}$ ) and subsequently were progressively withdrawn from alcohol. For that purpose, the water was progressively substituted for ethanol by steps of $4 \%(v / v)$ a week. The mice drank only water for at least 1 month before behavioral testing began. In all studies, alcohol-treated animals were compared to either pair-fed controls, which drank a dextrimaltose solution isocaloric to the alcohol one over the same period of treatment, or to mice submitted to a water and dry food diet ad-libitum (Béracochéa et al., 1985; 1987a, c). At the end of the alcohol treatment, alcohol-treated mice exhibited no weight loss as compared with control animals.

Behavioral testing was conducted following different periods of alcohol consumption. In parallel with memory testing, anatomical experiments were conducted to evaluate the effects of alcohol consumption on the neuronal density of several brain structures or on brain metabolic activity, using the 2-desoxyglucose technique.

Working memory was evaluated using spontaneous alternation, either in sequential or delayed procedures. Spontaneous alternation (SA) is the innate tendency of rodents whereby over a series of trials run in a T-maze, mice alternate at each successive trial the choice of the visited goal-arm, except for the first trial. Moreover, SA does not require the use of food reinforcement to emerge, which is of particular interest. Two procedures have been used.

In the sequential procedure, repetitive testing constitutes a potent source of proactive interference. Indeed, from trial to trial, an accurate performance at a given $\mathrm{N}$ trial requires that subjects are able to discriminate the specific target trial $\mathrm{N}-1$ from the interfering trial N-2. The target information required for successful performance varies from trial to trial, so that the subject is required not only to keep temporarily in short-term 
memory a specific information (for example what happened $30 \mathrm{sec}$ earlier) but also to reset it over successive runs. The resetting mechanisms and cognitive flexibility required to alternate over successive runs are major components of working memory processes.

In the delayed forced procedure, the acquisition phase involves two successive forced entries into the same goal arm of the maze, entrance into the other arm being blocked by a sliding door. In the test phase, which occurs after various delay intervals following acquisition, mice can freely enter both goal arms, the alternation response being to enter the arm opposite to the one entered during the acquisition phase. This procedure allowed the study of memory over long delay intervals (up to $48 \mathrm{~h}$ in our studies).

\section{CAC-induced memory impairment and brain damage}

We found that CAC produced an increased sensitivity to interference in the sequential procedure and an accelerated forgetting in the delayed one (Béracochéa et al., 1985; 1987a, c). Interestingly, these two impairments were not observed in mice submitted to a severe thiamine-deficient diet (Tako, 1986; Tako et al., 1991). We demonstrated that both exaggerated sensitivity to interference and accelerated forgetting exhibited by CAC-treated mice are due to a selective deficit of retrieval processes. Indeed, a change of the context of the maze, achieved by adding a large white cardboard at the end of the central alley, dramatically improves alternation rates at the cued test trial (Béracochéa et al., 1987b; 1989a). Insofar as alternation requires memory of the specific goal-arm entered at the acquisition phase (delayed procedure) or at the $\mathrm{N}-1$ trial (sequential procedure), the improvement of performance induced by the context-change shows that the target information required to alternate is not forgotten at the time of testing and that CACtreated mice suffer primarily from a retrieval impairment in usual testing conditions (Béracochéa et al., 1987c; 1989a).

In addition to memory impairment, we found that $\mathrm{CAC}$ also produces an abnormal emotional reactivity in an open-field and in elevated plus maze tasks. More specifically, CAC-treated animals enter more often and spend more time in the open arms of the elevated plus maze compared with controls. In the open field, CAC-treated mice exhibit the shortest latency to leave the center of the apparatus, and they exhibit more general activity than do controls. So far, CAC-treated mice are less 'anxious' than controls (unpublished results).

In parallel to the behavioral tasks, anatomical studies have shown that CAC produces a substantial cell loss (reduction of cell density) into the MB of the hypothalamus, a moderate cell loss in the anterior and mediodorsal thalamus (Béracochéa et al., 1987a) and in the frontal cortex, and a weak loss into the hippocampus (Béracochéa et al., 1985; 1987c; Lescaudron et al., 1984). At the end of the CAC period, the hippocampus also exhibits modifications in number and morphology of the dendritic spines of the CA1 hippocampal pyramidal neurons, but such alterations disappear after 1 month of withdrawal, namely, at the time of behavioral testing (Lescaudron et al., 1989).

Using the 2-desoxyglucose technique in mice, we found that MB exhibit a very large reduction of desoxy-glucose metabolic activity, which is dependent on the length of the alcohol treatment; this study also evidenced weak impairments in other diencephalic structures (the anterior and mediodorsal thalamus), but the hippocampal metabolic activity was spared (Bontempi et al., 1996).

Overall, the results of neuroanatomical studies stress that the pathology of the MB is the main lesion resulting from the CAC procedure used in our studies. Interestingly, we found that a very severe thiamine-deficient diet in the same strain of mice did not produce MB damage (Tako et al., 1991). 
Memory impairment resulting from discrete (CAC-treated mice) or experimental lesions of the MB: reversal by pharmacological compounds

Given our findings in CAC-treated animals, we investigated the effects of lesioning the $M B$ in non-alcoholic mice. For that purpose, an ibotenic acid solution $(10 \mathrm{mg} / \mathrm{mL})$ was injected in situ through a glass pipette. We found that this lesion generated the very same memory impairments as those resulting from CAC, namely, an exaggerated vulnerability to interference and an accelerated forgetting in the sequential and delayed alternation procedures respectively (Béracochéa \& Jaffard, 1987; Béracochéa \& Jaffard, 1990). The increased sensitivity to interference following MB damage was also evidenced in an 8-arm radial maze (Béracochéa et al., 1989). Moreover, as in CACtreated animals, the memory deficits observed in the alternation tasks also stem from retrievalmemory impairments (Tako et al., 1988). In addition, we also found that MB lesions reduce fear reactivity in an elevated plus maze task (Béracochéa \& Krazem, 1991), a finding also in agreement with our previous observations in CACtreated animals.

The similarity of the emotional and memory impairments resulting from $\mathrm{CAC}$ and $\mathrm{MB}$ lesions in non-alcoholic mice leads us to suggest that $\mathrm{MB}$ damage play a key role in the memory disturbances observed in CAC-treated mice. Given that MB exhibits the highest density of benzodiazepine receptors in the brain (Eymin et al., 1992), we administered methylbetacarboline, an inverse agonist of the benzodiazepines receptor having anxiogenic properties prior to memory testing. We observed that methylbetacarboline increases fear reactivity in the two experimental groups, which therefore behave similarly to controls in an elevated plus maze and, concomitantly, alleviate the retrieval-memory impairments in the sequential alternation task (Béracochéa et al., 1995a). In this study, we showed a high positive correlation between memory and 'anxiety' scores only for interfering trials of the sequential alternation task, namely, the trials involving a heavy memory load. The relationship between the emotional state of the subject and alternation scores of the interfering trials of the sequential alternation task was also conversely evidenced in non-alcoholic mice receiving diazepam at anxiolytic doses. We found that diazepam-treated animals exhibit memory deficits similar to those observed in CAC-treated or in MB-lesioned animals, both in the alternation tasks (Borde et al., 1997) or in an 8-arms radial maze involving a working memory component (Borde et al., 1998). Interestingly, we also observed similar deficits following diazepam administration, $\mathrm{CAC}$ or MB lesions in naive animals in a cognitive learning set task (Borde \& Béracochéa, 1999; Krazem et al., 1995).

Thus, the overall pharmacological data show that (a) benzodiazepine administration produces retrieval-memory deficits that are similar to those resulting from $\mathrm{CAC}$ or experimental MB lesions, (b) methylbetacarboline, an inverse agonist of the GABA/benzodiazepine receptor with anxiogenic properties, alleviates memory impairments resulting from discrete (CAC-treated mice) or from large experimental MB lesions, and (c) damage to the MB might play a key role in CAC-induced amnesia.

Given the resemblance between benzodiazepine-induced memory impairments and those resulting from $\mathrm{MB}$ lesions or CAC treatment, we hypothesized that emotional disturbances can be a causal factor of the memory impairments resulting from the $\mathrm{CAC}$ or $\mathrm{MB}$ lesions.

\section{THE MAMMILLARY BODIES: A SET OF NUCLEI AT THE INTE RFACE OF MEMORY AND EMOTIONAL PROCESSESS}

Our data emphasize the role of MB damage in CAC-induced amnesia and stress the importance of emotional impairments resulting either from 
discrete (CAC-treated animals) or from experimental MB lesions. Indeed, one additional set of MB functions that our studies highlight concerns the involvement of the $\mathrm{MB}$ in the interaction between emotional and memory processes. So far, we raise questions about the putative causal role of emotional dysfunction in the memory deficits resulting from $\mathrm{MB}$ damage or $\mathrm{CAC}$-treatment.

The involvement of the MB and surrounding nuclei in emotional processes has been documented. Lesions of the dorsal premammillary nucleus alter defensive behavior toward a predator, mainly by reducing the cognitive assessment of the predator's threat (Canteras et al., 1997; 2001; Blanchard et al., 2003). Anxiolytic effects of lesions of the medial MB nucleus (Béracochéa \& Krazem, 1991) or of the tuberomammillary nucleus (Frisch et al., 1998) have been reported during the exploration of an elevated plus maze. We also reported a deficit of contextual fear conditioning following MB damage, similar to the one generated by dorsal hippocampal lesions (Celerier et al., 2004; see also Radyuskin et al, 2005, for a negative report in mice suffering from a genetic ablation of the $\mathrm{MB}$, even though significant procedural differences could account for the discrepancies). In addition, we also reported deficits of fear conditioning following anterior thalamic damage, a brain structure tightly connected with the MB (Celerier et al., 2000). The MB-induced contextual fear conditioning deficit fits well with the observations that the medial mammillary nucleus plays a role in the hormonal response to stress. Indeed, it has been found that the normal increase of plasma corticosterone resulting from an acute stress is reduced in MB-lesioned animals (Suarez \& Perassi, 1988; 1993; see also Feldman et al., 1975), a finding also observed in rodents suffering from anterodorsal thalamic lesions after chronic stress (Suarez et al., 1999; 2001). According to Eymin et al. (1992), MB exhibit a very important density of $\mathrm{GABA} /$ benzodiazepine receptor sites, and $\mathrm{MB}$ were found to exhibit a dramatic reduction of glucose metabolism following the injection of low doses of diazepam (Ableitner et al., 1985; see also Schroeder et al., 1994). In keeping with these data, we showed that the memory improvement observed in CAC-treated mice following methylbetacarboline administration is specifically due to the enhancement of the desoxyglucose metabolic activity in the MB, which is normally reduced in alcoholtreated animals (Bontempi et al., 1996). Interestingly, MB have also been found to be a site of the antianxiety action of benzodiazepines in conflictpunishment procedures (Kataoka et al., 1982) or in mediating the anticonflict action of zopiclone (a cyclopyrrolone derivative, acting at the GABA receptor; Yamashita et al., 1989).

The observation that the MB are involved in emotional processes suggests that MB damage could lead to deficits in memory tasks that are likely to involve either an emotional component directly or to induce an emotional arousal, depending on the constraints of the tasks. For example, the cognitive demand involved in a given task (explicit versus implicit encoding or retrieval procedures) has been found to be differentially sensitive to benzodiazepines administration (Danion et al, 1989). In keeping with this idea, we showed that MB damage does not produce any deficit in a delayed matching to place task, requiring much more explicit demand than non-matching (alternating) ones, which are spontaneously processed in rodents (Béracochéa \& Jaffard, 1995). The memory load of a given task or the task difficulty (Schneider et al., 1996) could also induce emotional arousal and so far, MB damage should differentially affect performance. Accordingly, we found that CAC-treated mice, which exhibit significant discrete lesions of the MB, behave similarly as diazepam-treated mice in an 8 -arms radial maze. Furthermore, the largest deficits of both CAC or diazepam-treated mice were observed at the beginning of the behavioral sessions, but were no longer observed when the same types of problems were preceded by a mixed series of more 
complex ones (Borde et al., 1998; see also Sziklas \& Petrides, 1998, for the importance of the task difficulty in MB-induced deficits).

Thus, we suggest that the MB contributes to maintaining an emotional arousal and/or a moderate degree of 'anxiety', which are normally involved in the processing of memory tasks (Chapouthier et al., 2004); this emotional component may be of critical importance in spontaneous retrieval processes involved in 'working/episodic' memory tasks, in which information is bound up with specific contextual, emotional and temporal cues. Therefore, impairment of emotional arousal could be a causal factor for certain deficits exhibited by CAC-treated or MB-lesioned mice. Indeed, a weakness of emotional arousal can reduce attention and/or impair the processes involved during memory retrieval. In keeping with this idea, we showed that the alleviation of the retrieval-memory deficits exhibited by CAC-treated or MB-lesioned animals in the alternation tasks following a pre-test methylbetacarboline injection is specifically due to the interaction between the anxiolytic effects of the treatments (CAC or MB lesions) and the anxiogenic effects of the pharmacological compound (Béracochéa et al., 1995a; Borde et al., 1996; see also Borde et al., 1997).

Overall, the MB emerges as an important component of the interface between emotion and memory. Given its involvement in emotional processes, it follows that the MB should be involved in a wide range of memory processes and cognitive functions and so far, that $\mathrm{MB}$ damage may directly account for some of the complex neuropsychological features of the Korsakoff's syndrome.

\section{ACKNOWLEDGMENTS}

This study was supported by grants from the CNRS and GDA (Paris, France). The author wishes to thank Frances Ash (ashberac@free.fr) for her help in improving the English text.

\section{REFERENCES}

Ableitner A, Wuster M, Herz A. 1985. Specific changes in local cerebral glucose utilization in the rat brain induced by acute and chronic diazepam. Brain Res 16: 49-56.

Allen GV, Hopkins DA. 1989. Mamillary body in the rat: topography and synaptology of projections from the subicular complex, prefrontal cortex and midbrain tegmentum. J Comp Neurol 286: 311336.

Allen GV, Hopkins DA. 1990. Topography and synaptology of mamillary body projections to the mesencephalon and pons in the rat. J Comp Neurol 301: 214-231.

Béracochéa DJ, Jaffard R. 1985. Memory deficits subsequent to chronic consumption of ethanol in mice: an analysis based on spontaneous alternation behavior. Behav Brain Res 15: 15-25.

Béracochéa DJ, Jaffard R. 1987. Impairment of spontaneous alternation behavior in sequential test procedures following mammillary body lesions in mice evidence for time-dependent interference related memory deficits. Behav Neurosci 101: 187-197.

Béracochéa DJ, Jaffard R. 1990. Effects of mammillary bodies lesions on spontaneous or rewarded sequential alternation in mice. J Cognit Neurosci 2: 133-140.

Béracochéa DJ, Jaffard R. 1995. The effects of mammillary body lesions on delayed matching and delayed non matching to place tasks in the mice. Behav Brain Res 68: 45-52.

Béracochéa DJ, Krazem A. 1991. Effects of ibotenic acid lesions of the mammillary body and the mediodorsal thalamus on elevated plus maze exploration. Neuroreport 2: 793-796.

Béracochéa DJ, Lescaudron L, Verna A, Jaffard R. 1987a. Neuroanatomical effects of chronic ethanol consumption on dorsomedial and anterior thalamic nuclei and on substantia innominata in mice. Neurosci Lett 73: 81-84.

Béracochéa DJ, Lescaudron L, Tako A, Verna A, Jaffard R. 1987b. Build-up and release from proactive interference during chronic ethanol consumption in mice: a behavioral and neuroana- 
tomical study. Behav Brain Res 25: 63-74.

Béracochéa DJ, Tako A, Jaffard R. 1989a. Ageing and chronic ethanol consumption induce two different forms of amnesia. Psychobiology 17: 358-362.

Béracochéa DJ, Alaoui-Bouarraqui $F$, Jaffard $R$. $1989 \mathrm{~b}$. Impairment of memory in a delayed non matching to place task following mammillary bodies lesions in mice. Behav Brain Res 34: 147154.

Béracochéa DJ, Krazem A, Jaffard.R. 1995a. $\beta$-ccm reverses the memory deficits induced by a chronic ethanol administration and mammillary bodies lesions in mice. Psychobiology 23: 52-58.

Béracochéa DJ, Micheau J, Jaffard R. 1995b. Alteration of hippocampal and cortical cholinergic activities following lesions of the mammillary bodies in mice. Brain Res 670: 53-58.

Bontempi b, Beracochea DJ, Jaffard R, Destrade C. 1996. A 2-dg study of a long-term alcohol administration on regional metabolic activity in mice. Neuroscience 72: 1141-1153.

Borde N, Krazem A, Jaffard R, Béracochéa DJ. 1996. Effects of $\beta \mathrm{ccm}$ on memory impairments induced by chronic alcohol consumption in mice. Prog Neuropsychopharmacol Biol Psychiatry 20: 1377-1387.

Borde N, Krazem A, Jaffard R, Béracochéa DJ. 1997. Memory deficits following diazepam administration in mice: evidence for a time-dependent retrieval memory impairments. Psychobiology 25: 202-209.

Borde N, Jaffard R, Beracochea DJ. 1998. Effects of chronic alcohol consumption or diazepam administration on item recognition and temporal ordering in a spatial working memory task in mice. Eur $\mathbf{J}$ Neurosci 10: 2380-2387.

Borde N, Beracochea DJ. 1999. Effects of diazepam administration and chronic alcohol consumption on a spatial reversal learning in mice. Pharmacol Biochem Behav 62: 719-725.

Brokate B, Hildebrandt $\mathrm{H}$, Eling $\mathrm{P}$, Fichtner $\mathrm{H}$, Runge K, Timm C. 2003. Frontal lobe dysfunction in Korsakoff's syndrome and chronic alcoholism: continuity or discontinuity? Neuropsychology 17: 420-428.

Butters N. 1985. Alcoholic Korsakoff's syndrome: some unresolved issues concerning etiology, neuropathology, and cognitive deficits. J Clin Exp Neuropsychol 7: 181-210.

Butters N, Stuss DT. 1989. Diencephalic amnesia. In:
Boller E, Grafman J, eds, Handbook Of Neuropsychology, Amsterdam, the Netherlands: Elsevier, 3: 107-148.

Blanchard DC, Li Cl, Hubbard D, Markham CM, Yang M, Takahashi LK, et al. 2003. Dorsal premammillary nucleus differentially modulates defensive behaviors induced by different threat stimuli in rats. Neurosci Lett 345: 145-148.

Brand M, Fujiwara E, Kalbe E, Steingass Hp, Kessler J, Markowitsch HJ. 2003. Cognitive estimation and affective judgments in alcoholic korsakoff patients. J Clin Exp Neuropsychol 25: 324-334.

Cabanyes J. 2004. Neuropsychology of korsakoff syndrome. Neurologia 19: 183-192.

Canteras NS, Chiavegatto S, Valle LE, Swanson LW. 1997. Severe reduction of rat defensive behavior to a predator by discrete hypothalamic chemical lesions. Brain Res Bull 44: 297-305.

Canteras NS, Ribeiro-Barbosa ER, Comoli E. 2001. Tracing from the dorsal premammillary nucleus prosencephalic systems involved in the organization of innate fear responses. Neurosci Biobehav Rev 25: 661-668.

Celerier A, Ognard R, Decorte L, Béracochéa DJ. 2000. Deficits of spatial and non spatial memory and of auditory fear conditioning following anterior thalamic lesions in mice: comparison with chronic alcohol consumption. Eur J Neurosci 12: 25752584.

Celerier A, Pierard C, Béracochéa DJ. 2004. Effects of ibotenic acid lesions of the dorsal hippocampus on contextual fear conditioning in mice: comparison with mammillary bodies lesions. Behav Brain Res 151: 65-72.

Chapouthier G, Negroni J, Venault P. 2004. The pharmacology of anxiety and its consequences: epilepsy, balance control and memory processes. Current Topics in Pharmacology 8: 219-229.

Ciccia RM, Langlais PJ. 2000. An examination of the synergistic interaction of ethanol and thiamine deficiency in the development of neurological signs and long-term cognitive and memory impairments. Alcohol Clin Exp Res 24: 622-634.

Cruce JA. 1975. An autoradiographic study of the projections of the mammillothalamic tract in the rat. Brain Res 85: 21 1-219.

Cruce JA. 1 977. An autoradiographic study of descending connections of the mammillary nuclei of the rat. J Comp Neurol 176: 631-644.

Danion JM, Zimmermann MA, Willard-Schroeder D, 
Grange D, Singer L. 1989. Diazepam induces a dissociation between explicit and implicit memory psychopharmacology 99: 238-243.

Eymin C, Kopp N, Laurent B. 1992. Central benzodiazepine-binding sites in human cerebral structures associated with memory processes. Dementia 3: 232-238.

Feldman S, Confort N, Chowers I. 1975. Subcortical pathways involved in the mediation of adrenocortical responses following sciatic nerve stimulation. Neuroendocrinology 18: 359-365.

Fellgiebel A, Scheurich A, Siessmeier T, Schmidt LG, Bartenstein P. 2003. Persistence of disturbed thalamic glucose metabolism in a case of Wernicke-Korsakoff syndrome. Psychiatry Res 124: 105-112.

Freund G. 1973. Chronic central nervous system toxicity. Ann Rev Pharmacol 13: 217-227.

Frisch C, Hasenohrl RU, Krauth J, Huston JP: 1998. Anxiolytic-like behavior after lesions of the tuberomammillary nucleus e2-region. Exp brain Res 19: 260-264.

Gonzalo-Ruiz A, Alonso A, Sanz JM, Llinas RR. 1992. Afferent projections to the mammillary complex of the rat with special reference to those surrounding hypothalamic regions. J Comp Neurol 321: 277-299.

Harding A, Halliday G, Caine D, Kril J. 2000. Degeneration of anterior thalamic nuclei differentiates alcoholics with amnesia. Brain 123: 141-144.

Hayakawa T, Zyo K. 1984. Comparative anatomical study of the tegmentomammillary projections in some mammals: a horseradish peroxidase study. Brain Res 300: 335-349.

Hayakawa T, Zyo K. 1985. Afferent connections of gudden's tegmental nuclei in the rabbit. J Comp Neurol 235: 169-181.

Hildebrandt H, Muller S, Busman-Mork B, Goebel S, Eilers N. 2001. Are some memory deficits unique to lesions of the mammillary bodies? J Clin Exp Neuropsychol 23: 490-501.

Homewood J, Bond NW. 1999. Thiamin deficiency and Korsakoff's syndrome: failure to find memory impairments following nonalcoholic wernicke's encephalopathy. Alcohol 19: 75-84.

Homewood J, Bond NW, McGregor JC. 1991. The effects of chronic alcohol consumption or thiamine deficiency on radial-arm maze performance in the rat. Alcohol 8: 265-272.

Homewood J, Bond NW, Mc Kenzie A. 1997. The effects of single and repeated episodes of thiamin deficiency on memory in alcohol-consuming rats. Alcohol 14: 81-91.

Huppert FA, Piercy M. 1976. Temporal context and familiarity of material. Cortex 12: 3-20.

Irle E, Markowitsch HJ. 1983. Widespread neuroanatomical damage and learning deficits following chronic alcohol consumption or vitamin-b1 (thiamine) deficiency in rats. Behav Brain Res 9: 277-294.

Johnson MK, Kim JK. Risse G. 1985. Do alcoholic Korsakoff's syndrome patients acquire affective reactions? J Exp Psychol Learn Mem Cogn 11: 22-36.

Joyce EM. 1994. Aetiology of alcoholic brain damage: alcoholic neurotoxicity or thiamine malnutrition? Br Med Bull 50: 99-114.

Kataoka Y, Shibata K, Gomita Y, Ueki S. 1982. The mammillary body is a potential site of anti-anxiety action of benzodiazepines. Brain Res 10: 374-377.

Kopelman MD. 1995. The Korsakoff syndrome. $\mathrm{Br} \mathrm{J}$ Psychiatry 166: 154-173.

Krazem A, Béracochéa DJ, Jaffard R. 1995. Effects of mammillary bodies or mediodorsal thalamic lesions on the acquisition and retention of a learning set in mice: paradoxical effect of the intersession interval. Behav Brain Res 67, 51-58.

Krazem A, Marighetto A, Higueret P , Jaffard R. 2003. Age-dependent effects of moderate chronic ethanol administration on different forms of memory expression in mice. Behav Brain Res 17: 17-29.

Langlais PJ, Zhang SX. 1997. Cortical and subcortical white matter damage without wernicke's encephalopathy after recovery from thiamine deficiency in the rat. Alcohol Clin Exp Res 21: 434-443.

Lescaudron D, Béracochéa DJ, Verna A, Jaffard R. 1984. Chronic ethanol consumption induces neuronal loss in mammillary bodies of the mouse: a quantitative analysis. Neurosci Lett 50: 151-155.

Lescaudron L, Verna A, Jaffard R. 1989. Modifications in number and morphology of dendritic spines resulting from chronic ethanol consumption and withdrawal: a Golgi study in the mouse anterior and posterior hippocampus. Exp Neurol 106: 156-163.

Lhermitte F, Signoret JL. 1972. Analyse neuropsychologique et differentiation des syndromes amnésiques. Rev Neurol 126: 161-178.

Mair RG. 1994. On the role of thalamic pathology in 
diencephalic amnesia. Rev Neurosci 5: 105-140.

Mair RG, Anderson CD, Langlais PJ, Mc Entee WJ. 1988. Behavioral impairments, brain lesions and monoaminergic activity in the rat following recovery from a bout of thiamine deficiency. Behav Brain Res 27: 223-239.

Martin PR, Adinoff B, Lane E, Stapleton JM, Bone GA, Weingartner $\mathrm{H}$, et al. 1995. Fluvoxamine treatment of alcoholic amnesic disorder. European Neuropsychopharmacol 5: 27-33.

Moffoot A, O'Caroll RE , Murray C, Dougall N, Ebmeier K, Goodwin GM. 1994. Clonidine infusion increases uptake of ${ }^{99} \mathrm{Tc}$-Exametazime in anterior cingulate cortex in Korsakoff's psychosis. Psychol Med 24: 53-61.

Molina JA, Bermejo F, del Ser T, Jimenez-Jimenez FJ, Herranz A, Fernandez-Calle P, et al. 1994. Alcoholic cognitive deterioration and nutritional deficiencies. Acta Neurol Scand 89: 384-390.

Mumby DG, Mana MJ, Pinel JP, David E, Banks K. 1995. Pyrithiamine-induced thiamine deficiency impairs object recognition in rats. Behav Neurosci 109: 1209-1214.

Mayes AR, Meudell PR, Mann D, Pickering A. 1988. Location of lesions in the Korsakoff's syndrome. Neuropsychological and neuropathological data on two patients. Cortex 24: 367-388.

O'Carroll RE, Moffoot AP, Ebmeier KP, Goodwin GM. 1994. Effects of fluvoxamine treatment on cognitive functioning in the alcoholic Korsakoff syndrome. Psychopharmacology 116: 85-88.

Paller KA, Acharya A, Richardson AP, Plaisant O, Shimamura AP, Reed BR, et al. 1997. Functional neuroimaging of cortical dysfunction in alcoholic Korsakoff's syndrome. J Cognitive Neurosci 9: 277-293.

Parkin AJ, Blunden J, Rees JE, Hunkin NM. 1991. Wernicke-Korsakoff syndrome of nonalcoholic origin. Brain Cogn 15: 69-82.

Radyushkin K, Anokhin K, Meyer BI, Jiang Q, Alvarez-Bolado G, Gruss P. 2005. Genetic ablation of the mammillary bodies in the Foxbl mutant mouse leads to selective deficit of spatial working memory. Eur J Neurosci 21: 219-229.

Reed LJ, Lasserson D, Marsden P, Stanhope N, Stevens T, Bello F, et al. 2003. FDG-PET findings in the Wernicke-Korsakoff syndrome. Cortex 39: 1027-1045.

Savage LM, Chang Q, Gold PE. 2003. Diencephalic damage decreases hippocampal acetylcholine release during spontaneous alternation testing. Learn Mem 10: 242-246.

Schneider F, Gur RE, Alavi A, Seligman ME, Mozley LH, Smith RJ, et al. Cerebral blood flow changes in limbic regions induced by unsolvable anagram tasks. Am J Psychiatry 1996. 153: 206-212.

Seki M , Zyo K. 1984. Anterior thalamic afferents from the mammillary body and the limbic cortex in the rat. J Comp Neurol 229: 242-256.

Shibata H. 1988. A direct projection from the enthorinal cortex to the mammillary body in the rat. Neurosci Lett 90: 6-10.

Squire L, Amaral DG, Press GA. 1990. Magnetic resonance imaging of the hippocampal formation and mammillary nuclei distinguish medial temporal lobe and diencephalic amnesia. $\mathrm{J}$ Neurosci 10 : 3106-3117.

Suarez M, Perassi NI. 1988. Plasma corticosterone responses to lesions and stimulations of the limbic thalami nuclei, medial mammillary nucleus and cingulate cortex. Arch Int Physiol Biochim 96: 69-74.

Suarez M, Perassi NI. 1993. Adrenal response to acute stress in mammillary medial nuclei lesioned rats. Arch Int Physiol Biochim Biophys 101: 275-277.

Suarez M, Paglini P, Fernandez R, Enders J, Maglianesi M, Perassi N, et al. 1999. Influence of anterodorsal thalamic nuclei on the hypophysealadrenal axix and cardiac beta receptors in rats submitted to variable chronic stress. Acta Physiol Pharmacol Ther Latinoam 49: 71-78.

Suarez MM, Rivarola MA, Molina SM, Perassi NI, Levin GM, Cabrera R. 2001. Periodic maternal deprivation and lesion of anterodorsal thalamic nuclei induce alteration on hypophyso adrenal system activity in adult rats. Life Sci 69: 803813.

Swanson LW, Cowan WM. 1975. An autoradiographic study of the organization of the efferent connections of the hippocampal formation in the rat. $\mathrm{J}$ Comp Neurol 172: 49-84.

Sziklas V, Petrides M. 1998. Memory and the region of the mammillary bodies. Prog Neurobiol 54: 55-70.

Tako A. 1986. Etude neuropsychologique des amnésies diencéphaliques d'origine alcoolique et carentielle chez la souris. Doctoral dissertation, Université de Bordeaux 1, 1-130.

Tako A, Beracochea D, Jaffard, R. 1988. Accelerated rate of forgetting for spatial information following mammillary bodies lesion in mice: a retrieval 
deficit alleviated by a context change occurring on the retention test. Psychobiology 16: 45-53.

Tako A, Beracochea D, Lescaudron L, Jaffard, R. 1991. Effects of a chronic ethanol consumption and thiamine deficiency on spatial working memory in mice: a behavioral and neuroanatomical study. Neurosci Lett 123: 37-40

Thompson R. 1981. Rapid forgetting of spatial habit in rats with hippocampal lesions. Science 212: 959-960.

Vann SD, Aggleton JP. 2004. The mammillary bodies: two memory systems in one? Nat Rev Neurosci 5: 35-44.

Victor M, Adams RD, Collins GH. 1989. The Wernicke-Korsakoff's Syndrome and Related Neurological Disorders due to Alcoholism and Malnutrition. 2nd ed. Philadelphia, Pennsylvania, USA: FA Davis.

Walker DW, Barnes DE, Zornetzer SF, Hunter BE, Kubanis P. 1980. Neuronal loss in hippocampus induced by prolonged ethanol consumption in rats. Science 209: 711-713.

Warrington EK, Weiskrantz L. 1974. The effect of prior learning on subsequent retention in amnesic patients. Neuropsychologia 12: 419-428.

Wiit ED, Goldman-Rakic PS. 1983a. Intermittent thiamine deficiency in the rhesus monkey. $i$. Progression of neurological signs and neuroanatomical lesions. Ann Neurol 13: 376395.

Wiit ED, Goldman-Rakic PS. 1983b. Intermittent thiamine deficiency in the rhesus monkey. ii. Evidence for memory loss. Ann Neurol 13: 396401.

Yamashita K, Kataoka A, Shibata K, Tominaga K, Ueki S. 1989. A key role of the mammillary body in mediation of the antianxiety action of zopiclone, a cyclopyrrolone derivative. Jpn J Pharmacol 51: 438-442.

Zola-Morgan S, Squire L. 1985. Amnesia in monkeys after lesions of the mediodorsal nucleus of the thalamus. Ann Neurol 17: 558-564. 

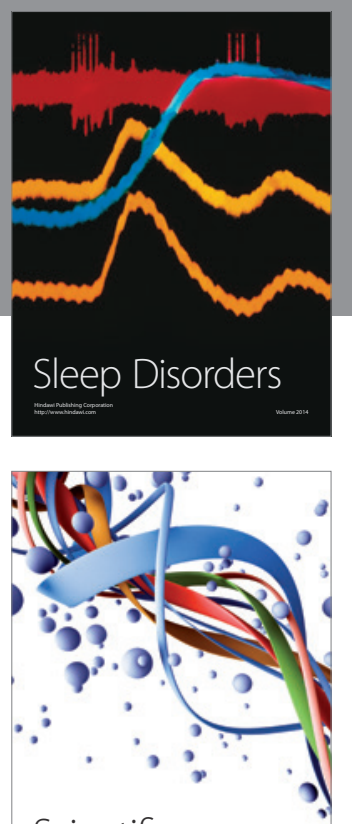

Scientifica
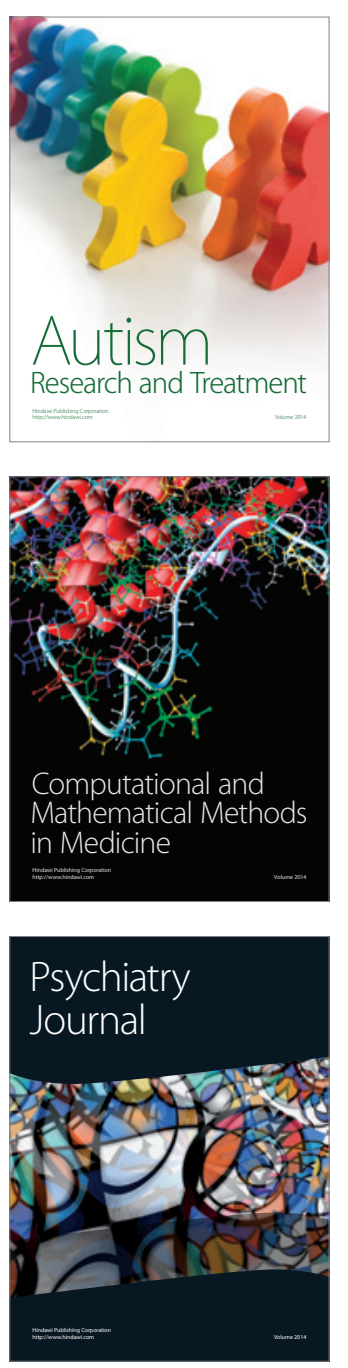
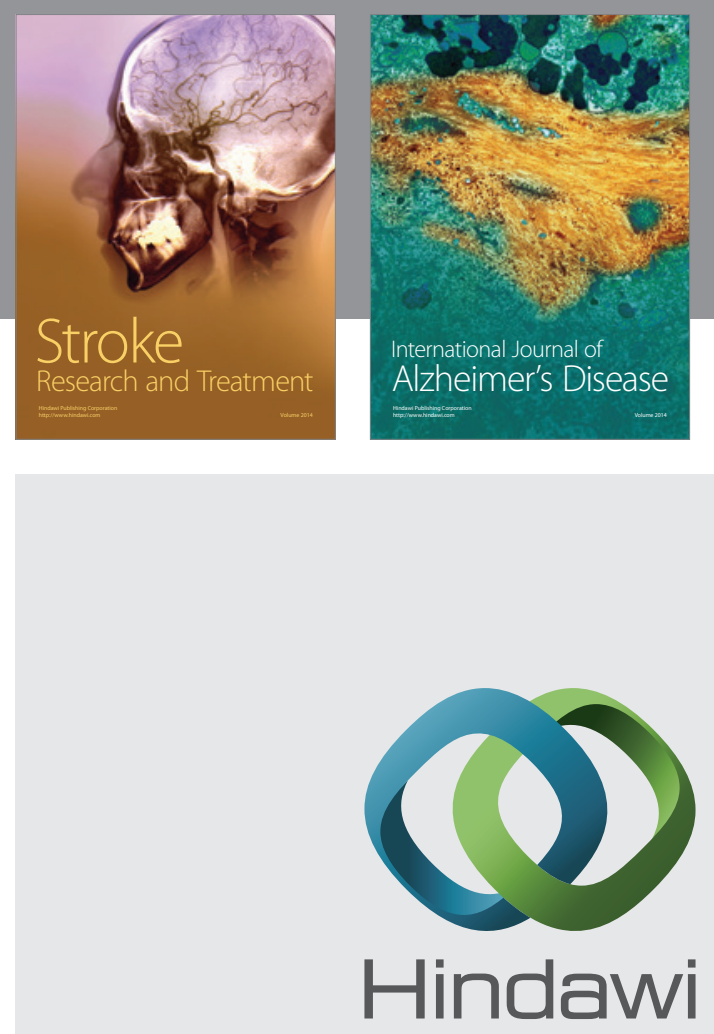

Submit your manuscripts at

http://www.hindawi.com
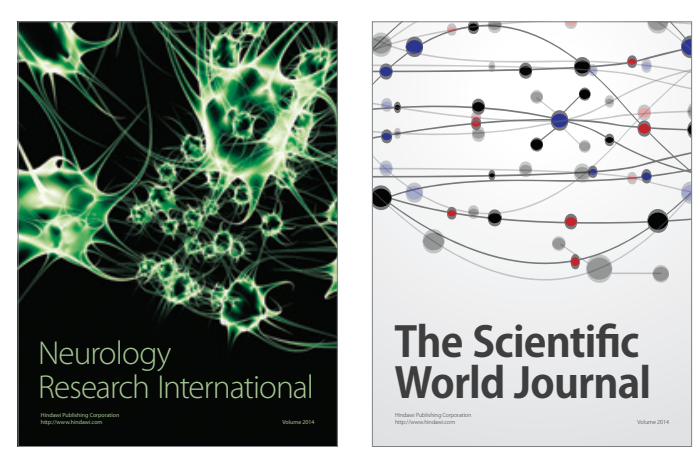

The Scientific World Journal

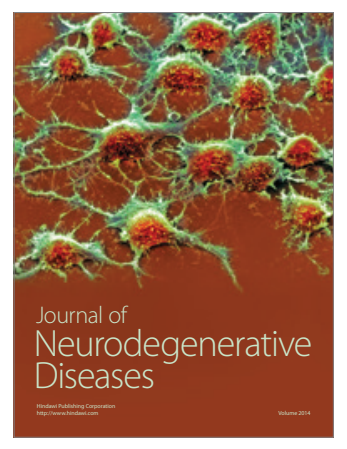

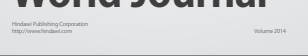

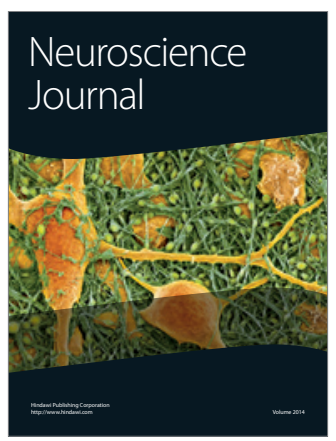

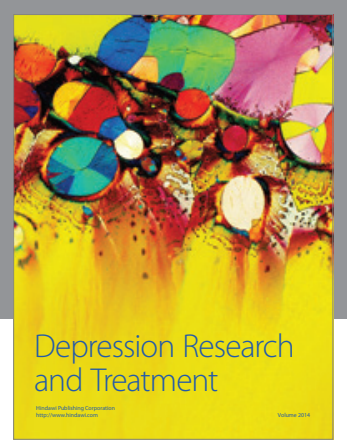
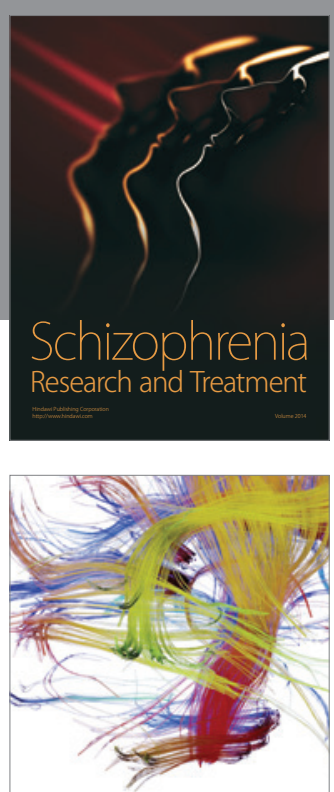

Brain Science

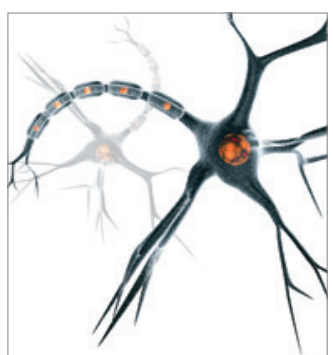

Neural Plasticity
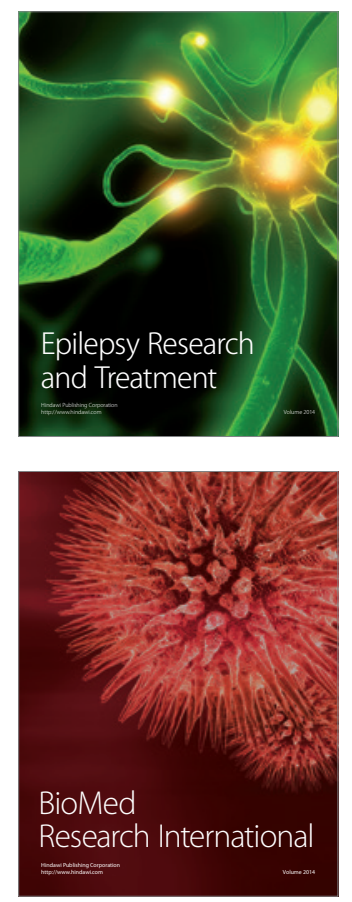

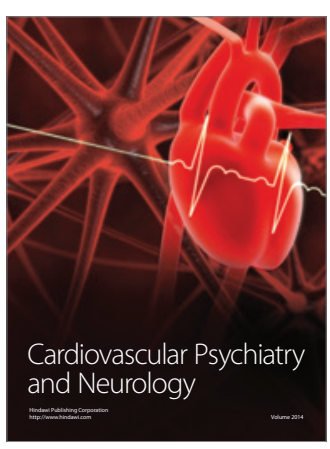

Parkinson's

Disease
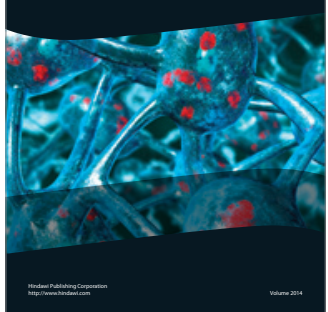